\title{
Drug Utilization Pattern and Potential Teratogenicity Risk among Pregnant Women Visiting Antenatal Clinic: The Case of a Primary Hospital
}

\author{
Mesfin Fikadu, Dereje Kebebe, Wote Amelo and Fanta Gashe* \\ Department of Pharmacy, College of Public Health and Medical Sciences, Jimma University, Ethiopia.
}

\begin{abstract}
Background: Pregnancy is a special physiological condition where the treatment needs a special concern. Moreover, pharmacotherapy during pregnancy is very challenging since only a few medicines have been specifically tested for safety. Objective: The aim of this study was to evaluate the utilization pattern and the teratogenicity risk of the drugs prescribed to pregnant women in Fiche Hospital, Ethiopia. Methods: A retrospective study was conducted by reviewing medical case files of 323 pregnant women, encountered with at least one drug, out of 1876 pregnant women attending antenatal clinic from February 09/2013 to March 09/2014. The prescription pattern was assessed from perspectives of World Health Organization (WHO) core drug use indicators, and the United States Food and Drug Administration (FDA) fetal harm classification. Results: Among 1876 pregnant women who visited ANC clinic, a total of 323 women received 456 medications. The age of the patients was within the range of $16-49$ years and the majority of them $(77.22 \%)$ were within the age group of 20 -35 years. The majority of pregnant women $(80.47 \%)$ visited antenatal care (ANC) during their first trimester gestation. Out of the total drugs prescribed, category A drugs comprised $20.83 \%$, category B $(26.34 \%)$, category C (24.34\%), category C/D $(9.65 \%)$, category D $(9.43 \%)$ and category $X(1.09 \%)$. Percentage of encounter with antibiotics and injectable drugs were $31.8 \%$ and $19.30 \%$, respectively. Conclusion: Approximately half of the pregnant women utilized drugs from FDA category $C, D$ and $X$ which are thought to cause fetal harm; therefore, the use of these drugs should be minimized.
\end{abstract}

Key words: FDA drug category, Pregnancy, Teratogen, Trimester, WHO core drug prescribing indicators.

\section{INTRODUCTION}

The majority of medicinal products administered to a pregnant woman could have effects on the fetus. ${ }^{1,2}$ Hence, medicine prescribing in pregnancy would require good knowledge of teratogenicity, fetal and neonatal effects that are associated with the medicines under considerations. ${ }^{3}$ Therefore, in order to optimize the knowledge about any potential teratogenic effects of a drug and the doses at which such effects will develop, it is desirable to gather information about all medicinal products taken by pregnant women., ${ }^{2,4}$

Medication use during pregnancy has been an issue of concern since the discovery of birth defects resulting from Thalidomide use in early pregnancy during the $1960 \mathrm{~s} .{ }^{4,5}$ Pharmacological treatment should be avoided in pregnancy, unless absolutely necessary. ${ }^{6-8}$
Pregnant women are generally excluded, for ethical reasons, from randomized clinical trials in drug development. This has left questions about the safety of new medications on the developing fetus unanswered, upon drug approval and marketing. ${ }^{9,10}$ However, to guide safe drug use during pregnancy, the U.S.A. Food and Drug Administration (FDA) classified drugs into the following major categories; A, B, C, D, and X with categories $\mathrm{D}$ and $\mathrm{X}$ indicating evidence of risk in pregnancy. ${ }^{11-13}$

Inappropriate use of medications by pregnant women has been widely reported in different countries. ${ }^{14-16}$ In Fitche Hospital there was no such study before for the safety and effectiveness of drug use during pregnancy. Hence, this study was carried
Submitted date :28-Jan-2015 Accepted date :27-Mar-2015

DOI: $10.5530 / \mathrm{ijopp} .8 .1 .6$

Address for correspondence:

Mr. Fanta Gashe,

Department of Pharmacy,

College of Public Health and

Medical Sciences, Jimma

University, P.O.box:378

Ethiopia.

Phoneno: +251-910553477

E-mail :fantwark@gmail.com

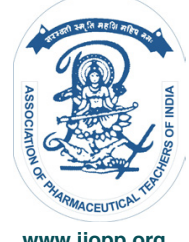

www.ijopp.org 


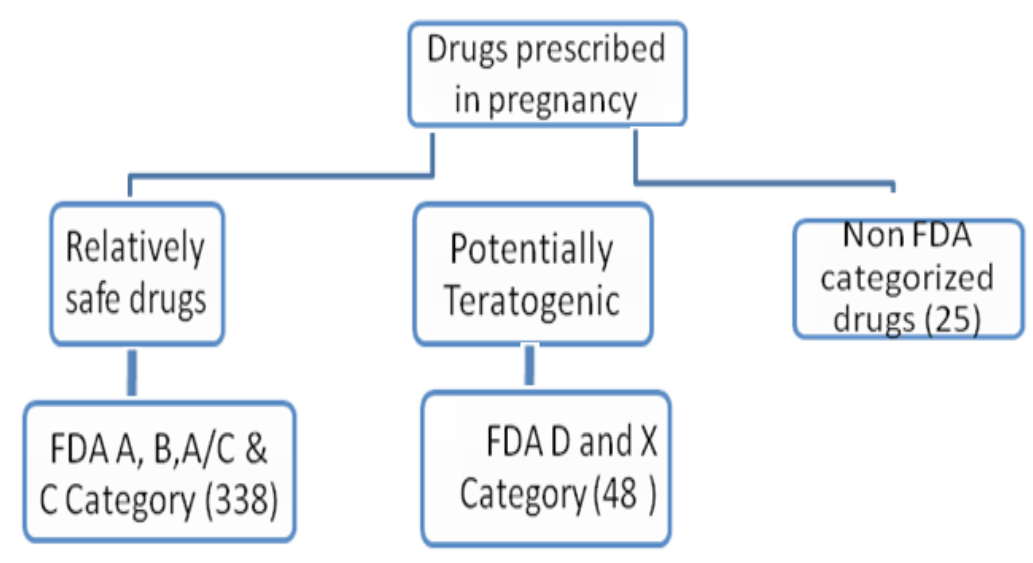

Graphical Abstract

out to evaluate the pattern of drug use and potential teratogenicity risk to fetus in women attending the antenatal clinic.

\section{METHODS}

Retrospective study was conducted on pregnant women who were on ANC follow up in the last one year of the study period from February 2013 to January 2014 in Fiche Hospital, Ethiopia. All the pregnant women who visited greater than or equal to two times in their gestational period and the prescribed drugs which clearly corresponds with the trimesters were included in the study. During the specified study period, 2162 pregnant women were registered on ANC registration book; however, only 1876 patient medical records actually presented in the card room. Hence, 1876 patient medical records were reviewed. Required information like Patient age, address, gravidae, drugs prescribed, dosage form, route of administration, main diagnosis, the trimester during drug administration, and other related issues were collected from the patients profile using a structured data collection sheet. The collected data was checked manually for completeness. Then, the data was coded and analyzed using FDA pregnancy drug category and WHO core prescribing indicators.

Research on pregnant women raises a unique set of ethical concerns due to possible crimes committed by disclosing medical information. Therefore, before data collection, a formal letter was obtained from the Jimma University. Ethical clearance was obtained from ethical clearance committee of College of Public Health and Medical Sciences. Then, the letter was given to the administrator of Fiche Hospital. Privacy and confidentiality were given attention throughout the study.

\section{RESULTS}

Among 1876 pregnant women who visited ANC clinic and whose patient medical records presented in the card room, a total of 323 women received 456 medications during the specified study period. The age of the patients was within the range of 16-49 years and the majority of them were within the age group of 20-35 years $(77.22 \%)$, which represents the normal reproductive age group. Among the total pregnant women, $43.00 \%$ were secundum gravidae, $32.00 \%$ primigravidae, and $23.07 \%$ multigravidae, but for $2.07 \%$ of them gravidae was not indicated. Most of the pregnant women visited ANC clinic during the first trimester (61\%) followed by second and third trimesters which account for 25\%,13.61\%, respectively. Majority (80.47\%) of them visited the ANC clinic three to five times throughout their pregnancy period (Table 1). Among the 323 pregnant women who got at least one medication during their visit, $43.96 \%$ were in their first trimester; $32.84 \%$ in their second trimester and $23.20 \%$ in their third trimester (Figure 1).

Among medical conditions to which drugs were prescribed in different trimesters, gastro intestinal disorders was the main ailment $(63.16 \%)$ which comprises $31.73 \%, 38.49 \%$ and $36.62 \%$ in first, second and third trimester, respectively. From the total diseases recorded dyspepsia (36) and urinary tract infection (26) were the major diseases in the first trimester and second trimester gestation, respectively. Urinary tract infection was also common in the first trimester and third trimester gestations (Table 2).

From the total dosage forms prescribed to the pregnant women, more than half of them $(57.02 \%)$ were in tablet dosage form. It was the most commonly prescribed dosage form across all trimesters. Others like solution, capsule and syrup were also frequently prescribed (Table 3). Dosage forms such as tablets, capsules and syrup were administered orally while solution was mainly pre- 


\begin{tabular}{|c|c|c|c|c|c|}
\hline Parameter & Frequency & Percentage & $45.00 \%$ & & \\
\hline \multicolumn{3}{|l|}{ Gravidae } & $35.00 \%$ & & \\
\hline Primigravida & 75 & $23.22 \%$ & $30.00 \%$ & & \\
\hline Secundum gravida & 137 & $42.41 \%$ & $25.00 \%$ & & \\
\hline Multigravida & 104 & $32.20 \%$ & $20.00 \%$ & & \\
\hline Gravidae not indicated & 7 & $2.17 \%$ & $15.00 \%$ & & \\
\hline \multicolumn{3}{|l|}{ Time of first ANC visit } & $10.00 \%$ & & \\
\hline First trimester & 200 & $61.92 \%$ & $\begin{array}{l}5.00 \% \\
0.00 \%\end{array}$ & & \\
\hline Second trimester & 81 & $25.08 \%$ & \multicolumn{3}{|c|}{ 1st trimester 2 nd trimester 3 rd trimester } \\
\hline Third trimester & 42 & $13.00 \%$ & & & \\
\hline \multicolumn{3}{|l|}{ Total numbers of ANC visit } & \multicolumn{3}{|c|}{$\begin{array}{l}\text { Figure 1: Frequency distribution of trimesters in } \\
\text { women encountered with at least one dru }\end{array}$} \\
\hline Two times & 55 & $17.03 \%$ & & & \\
\hline $3-5$ times & 262 & $81.11 \%$ & & & \\
\hline$>5$ times & 6 & $1.86 \%$ & & & \\
\hline \multicolumn{2}{|c|}{$1^{\text {st }}$ trimester } & \multicolumn{2}{|c|}{$2^{\text {nd }}$ trimester } & \multicolumn{2}{|c|}{$3^{\text {rd }}$ trimester } \\
\hline Diagnosis & Frequency & Diagnosis & Frequency & Diagnosis & Frequency \\
\hline Dyspepsia & 36 & UTI & 26 & HEG & 17 \\
\hline CAP & 30 & Dyspepsia & 24 & UTI & 14 \\
\hline UTI & 27 & CAP & 11 & $\begin{array}{l}\text { Abdominal } \\
\text { discomfort }\end{array}$ & 15 \\
\hline AFI & 25 & AFI & 10 & PUD & 9 \\
\hline $\begin{array}{l}\text { Abdominal } \\
\text { Discomfort }\end{array}$ & 25 & $\begin{array}{l}\text { Abdominal } \\
\text { discomfort }\end{array}$ & 7 & Anemia & 7 \\
\hline PUD & 20 & PUD & 6 & Preeclampsia & 6 \\
\hline Diarrhea & 21 & HEG & 4 & Diarrhea & 17 \\
\hline Trachoma & 13 & Trachoma & 1 & - & - \\
\hline Others & 12 & Others & 11 & Others & 11 \\
\hline
\end{tabular}

HEG=Hyperemesis Gravidarum, UTI=urinary tract infection, AFI=acute febrile illness, PUD=Peptic ulcer diseases, CAP=CommunityAcquired Pneumonia

\section{Table 3: Distribution of dosage forms prescribed to pregnant women who attended ANC follow up}

\begin{tabular}{lcccc} 
Dosage form & \multicolumn{4}{c}{ Frequency $(\%)$} \\
& $\mathbf{1}^{\text {st }}$ trimester & $\mathbf{2}^{\text {nd }}$ trimester & 3 $^{\text {rd trimester }}$ & Total \\
\hline Tablet & $139(60.46)$ & $86(59.72)$ & $37(45.12)$ & $262(57.46)$ \\
Capsule & $15(6.52)$ & $17(11.81)$ & $10(12.20)$ & $42(9.21)$ \\
Syrup & $18(7.69)$ & $14(9.72)$ & $7(8.53)$ & $39(8.55)$ \\
Gels & $5(2.17)$ & $3(2.08)$ & $1(1.22)$ & $9(1.97)$ \\
Vaginal cream & $1(0.43)$ & $2(1.39)$ & 0 & $3(0.66)$ \\
Solution & $39(17.08)$ & $21(14.58)$ & $27(32.93)$ & $87(19.08)$ \\
Ointment & $13(5.65)$ & $1(0.69)$ & 0 & $14(3.07)$ \\
Total & $230(100)$ & $144(100)$ & $82(100)$ & $456(100)$ \\
\hline
\end{tabular}

scribed to be administered via intravenous route in all trimesters (Table 4).

From the total drugs prescribed for the pregnant women, FDA category B drugs $(26.75 \%)$ were the most commonly prescribed drugs followed by category C, A,
C/D, D which account for $24.34 \%, 20.83 \%, 9.65 \%$, and $9.43 \%$, respectively. FDA category A/C $(2.20 \%)$ and category X $(1.09 \%)$ were the least prescribed drugs. Category A drugs were highly utilized in second trimester $(10.53 \%)$ while category B, C, D drugs were the most 


\begin{tabular}{|c|c|c|c|c|}
\hline \multirow{2}{*}{$\begin{array}{c}\text { Route of } \\
\text { administration }\end{array}$} & \multicolumn{4}{|c|}{ Frequency (\%) } \\
\hline & $1^{\text {st }}$ trimester & $2^{\text {nd }}$ trimester & $3^{\text {rdtrimester }}$ & Total \\
\hline PO & $172(74.78)$ & $117(81.25)$ & $54(65.85)$ & $343(75.22)$ \\
\hline IV & $34(14.78)$ & $18(12.50)$ & $26(31.71)$ & $78(17.11)$ \\
\hline IM & $5(2.17)$ & $3(2.08)$ & $1(1.22)$ & $8(1.75)$ \\
\hline Vaginal & $6(2.60)$ & $5(3.47)$ & $2(2.44)$ & $13(2.85)$ \\
\hline Topical & $13(5.65)$ & $1(0.69)$ & 0 & $14(3.07)$ \\
\hline
\end{tabular}

$\mathrm{IM}=$ intramuscular, $\mathrm{IV}=$ intravenous, $\mathrm{PO}=$ oral route

\begin{tabular}{|c|c|c|c|c|}
\hline $\begin{array}{l}\text { FDA drug } \\
\text { category }\end{array}$ & $1^{\text {st }}$ trimester & $2^{\text {nd }}$ trimester & $3^{\text {rd }}$ trimester & Total \\
\hline A & $37(8.11 \%)$ & $49(10.74 \%)$ & $10(2.2 \%)$ & $95(20.83 \%)$ \\
\hline$A / C$ & $6(1.32 \%)$ & $4(0.88 \%)$ & 0 & $10(2.2 \%)$ \\
\hline B & $53(11.62 \%)$ & $36(7.9 \%)$ & $33(7.24 \%)$ & $122(26.75 \%)$ \\
\hline C & $61(13.38 \%)$ & $35(7.67 \%)$ & $19(4.17 \%)$ & $111(24.34 \%)$ \\
\hline C/D & 27 (5.92\%) & $9(1.97 \%)$ & $4(0.88 \%)$ & $44(9.65 \%)$ \\
\hline D & $32(7.01 \%)$ & $4(0.88 \%)$ & $7(1.53 \%)$ & $43(9.43 \%)$ \\
\hline$x$ & $5(1.09 \%)$ & 0 & 0 & $5(1.09 \%)$ \\
\hline $\begin{array}{l}\text { Not-FDA } \\
\text { Categorized }\end{array}$ & $9(1.97 \%)$ & $7(1.53 \%)$ & $9(1) 09 \%$. & $25(5.5 \%)$ \\
\hline
\end{tabular}

$A / C=$ Refers to manufacturer's difference in categorizing drugs, $C / D=$ Categorized as $D$ above 30 weeks of pregnancy

\section{Table 6: FDA category of drugs prescribed to pregnant women}

\begin{tabular}{|c|c|c|}
\hline $\begin{array}{l}\text { FDA drug } \\
\text { category }\end{array}$ & Frequency & Representative drugs \\
\hline A & $95(20.83 \%)$ & $\begin{array}{l}\text { Ferrous sulphate, folic acid,multivitamine, pyridoxine vitamin B } \\
\text { complex, }\end{array}$ \\
\hline $\mathrm{A} / \mathrm{C}$ & $10(2.2 \%)$ & Magnesium trisilicate, magnesium sulphate, \\
\hline B & $122(26.75 \%)$ & $\begin{array}{c}\text { Ampicillin, metoclopramide, ceftriaxone, Amoxicillin Amoxicillin/ } \\
\text { clavulinic acid, erythromycin, cephalexin, cloxacillin, meclizine, } \\
\text { metronidazole, methyldopa, chloramphenicol eye ointment, } \\
\text { paracetamol }\end{array}$ \\
\hline C & $111(24.34 \%)$ & $\begin{array}{l}\text { Norflxacillin, chloramphenicol, antacidsyrup, cimetidine, omeprazole, } \\
\text { dexamethasone eye ointment., mebendazole, hyosine, ketoconazole } \\
\text { gel, nifedipine, promethazine, tramadol, amitriptyline, furosemide, } \\
\text { cotrimoxazole, hydralizine, hydrocortisone, vitamin K, bisacodyl, } \\
\text { indomethacin, albuterol, chlorpromazine, calcium gluconate. }\end{array}$ \\
\hline C/D & $44(9.65 \%)$ & Ibuprofen, enalapril, diclofenac \\
\hline D & $43(9.43 \%)$ & $\begin{array}{l}\text { Doxycycline, gentamicin, tetracycline eye ointment, diazepam, } \\
\text { phenytoin }\end{array}$ \\
\hline $\mathbf{x}$ & $5(1.09 \%)$ & Misoprostol \\
\hline $\begin{array}{l}\text { Non-FDA } \\
\text { Categorized }\end{array}$ & $25(5.5 \%)$ & maintenance fluids, combined cough syrup \\
\hline
\end{tabular}

frequently prescribed drugs during the first trimester comprising $11.62 \%, 13.38 \%$ and $7.01 \%$, respectively. Category $\mathrm{X}$ was prescribed only during the first trimester. Category C and D together constituted $52.17 \%$, $33.57 \%$ and $36.58 \%$ in first, second, and third trimester, respectively. Category D and X together comprised $16.08 \%, 2.79 \%$ and $8.53 \%$ in first, second and third trimesters, respectively. Out of the total drugs prescribed, category C, D and X all together comprised 44.61\% (Table 5).

All the FDA category A drugs prescribed for patients were minerals and vitamins; namely, ferrous sulphate, folic acid, multivitamin, vitamin B complex and pyridoxine. The majority of category $\mathrm{B}$ drugs prescribed for pregnant women were antibiotics such as ampicillin, ceftriaxone, amoxicillin, amoxicillin/clavulinic acid, 


\begin{tabular}{lccc}
\multicolumn{1}{c}{ Table 7: Distribution of FDA categories D and X drugs prescribed for pregnant women } \\
\hline \multicolumn{1}{c}{ Drugs } & Indication & FDA category & Frequency \\
\hline Doxycycline & UTI & D & 13 \\
Gentamicin & UTI & D & 7 \\
Chlorpromazine & HEG & D & 2 \\
Tetracycline ointment & Trachoma & D & 8 \\
Diazepam & Preeclampsia & D & 6 \\
Phenobarbital & epilepsy & D & 3 \\
Phenytoin & epilepsy & D & 4 \\
Misoprostol & Labor & X & 5 \\
\hline
\end{tabular}

HEG: Hyperemesis Gravidarum, UTI: urinary tract infection

\section{Table 8: Prescribing pattern indicators with respective WHO references}

\begin{tabular}{|c|c|c|c|c|c|}
\hline \multirow{2}{*}{ Indicators } & \multicolumn{5}{|c|}{ Value n (\%) } \\
\hline & $1^{\text {st }}$ trimester & $2^{\text {nd }}$ trimester & $3^{\text {rd }}$ trimester & Total & Reference \\
\hline $\begin{array}{l}\text { Average number } \\
\text { of drugs per } \\
\text { prescription }\end{array}$ & $\begin{array}{c}230 / 142 \\
(1.62)\end{array}$ & $\begin{array}{c}144 / 106 \\
(1.34)\end{array}$ & $\begin{array}{l}82 / 75 \\
(1.09)\end{array}$ & $\begin{array}{c}456 / 323 \\
(1.41)\end{array}$ & $1.6-1.8$ \\
\hline $\begin{array}{l}\text { Percentage } \\
\text { of encounters } \\
\text { with antibiotics } \\
\text { prescribed }\end{array}$ & $\begin{array}{c}74 / 230 \\
(32.17 \%)\end{array}$ & $\begin{array}{c}37 / 144 \\
(25.87 \%)\end{array}$ & $\begin{array}{c}34 / 82 \\
(41.46 \%)\end{array}$ & $\begin{array}{l}145 / 456 \\
(31.8 \%)\end{array}$ & $20-26.8$ \\
\hline $\begin{array}{l}\text { Percentage of } \\
\text { encounters with } \\
\text { an injection } \\
\text { prescribed }\end{array}$ & $\begin{array}{r}36 / 230 \\
(15.65 \%\end{array}$ & $\begin{array}{c}23 / 144 \\
(16.08 \%)\end{array}$ & $\begin{array}{c}29 / 82 \\
(35.36 \%)\end{array}$ & $\begin{array}{c}88 / 456 \\
(19.30 \%)\end{array}$ & $13.4-24.1$ \\
\hline $\begin{array}{l}\text { Percentage of } \\
\text { drugs Prescribed } \\
\text { by generic name }\end{array}$ & $\begin{array}{r}215 / 230 \\
(93.48 \%)\end{array}$ & $\begin{array}{c}137 / 144 \\
(95.10 \%)\end{array}$ & $\begin{array}{c}77 / 82 \\
(93.90 \%)\end{array}$ & $\begin{array}{c}429 / 456 \\
(94.08 \%)\end{array}$ & 100 \\
\hline
\end{tabular}

erythromycin, cephalexin, cloxacillin and chloramphenicol eye ointment. On other hand, mixed types of drugs were used from FDA C category drugs (Table 6). Category D drugs, which are considered to be risky both to pregnant women and fetus, including doxycycline, gentamicin, chlorpromazine, tetracycline eye ointment, diazepam and phenytoin were also prescribed in the specified study period. In addition, category $\mathrm{X}$ drug (misoprostol) was prescribed 5 times (Table 7).

Majority of the drugs (94.08\%) were prescribed by their generic names which was almost the same across all trimesters. Average numbers of drugs per prescription was 1.41 , but this figure was relatively higher in first trimester (1.62). Percentages of encounters with antibiotics were $32.17 \%, 41.46 \%, 25.87 \%$ in first, second and third trimesters, respectively. The percentage of prescriptions with an injection prescribed was $19.3 \%$. Most of injections containing prescriptions $(35.36 \%$ ) were prescribed in third trimester (Table 8).

\section{DISCUSSION}

Out of 323 pregnant women on ANC follow up, the majority of them were between 20 to 35 years which represents the normal reproductive age groups. This is in accordance with the observation reported by Joshi $e t$ al. ${ }^{17}$ Greater than half of the patients visited antenatal OPD for the first time during their first trimester, and secundum gravida constituted relatively high percent of the women attending the ANC. This finding is similar to the observation made in Adama Referral Hospital. ${ }^{18}$

Among pregnant women encountered with at least one drug, first trimester (43.96\%) comprised relatively large number of pregnant women followed by second $(32.84 \%)$ and third trimesters $(23.20 \%)$. This finding is incomparable with other reports made by various researchers. ${ }^{17,19}$

Most common diseases recorded were hyperemesis gravidarum, urinary tract infection, peptic ulcer diseases, dyspepsia and abdominal discomfort. Hence, the majority of medications prescribed were drugs used against gastrointestinal disorders such as metoclopramide, metronidazole, magnesium trisilicate, cimetidine, omeprazole, mebendazole, chlorpromazine and hyosine. All of these drugs are either from FDA category A, B or C.

Oral dosage form was the main dosage form used across all trimesters $(75.22 \%)$ as it is the simplest and easiest way for any patient to take a medication. Injectable products were also frequently used in all trimes- 
ter gestations, commonly administered via intravenous route. This is probably due to most of the pregnant women were admitted for the hyperemesis gravidarum (HEG) in which they took different parental drugs such as anti emetics, anti pain, IV fluids, antibiotics and others per drug encounter. ${ }^{19}$

The FDA category A drugs prescribed for pregnant women were minerals and vitamins which include ferrous sulphate, folic acid, multivitamin, vitamin B complex and pyridoxine. These comprised $20.83 \%$ from total drugs prescribed for patients. In contrast, the studies conducted in the USA and Nigeria revealed that less number of category A drugs were prescribed. ${ }^{16,20}$

In this study, about $27 \%$ of drugs prescribed were FDA category B drugs. This finding is different from various studies which is relatively less compared to the observation made by various researches, ${ }^{14,16,18}$ however, it is more than the finding of the study reported by other researcher. ${ }^{17}$ The majority of category $\mathrm{B}$ drugs were antibiotics mainly prescribed for diseases like urinary tract infections.

Category C drugs prescribed in all trimesters were $24.34 \%$. Compared to the studies done in USA, ${ }^{14,16}$ it is relatively less. Therefore, the prescribing pattern of potentially harmful drugs to pregnant women was comparatively low in the present study.

Category D drugs were prescribed in about $9.3 \%$ of pregnant women. Various researchers reported comparatively less finding than the present study. ${ }^{15,16,21}$ On other hand it was reported that large numbers of category $\mathrm{D}$ drugs were prescribed in another studies. ${ }^{17,22}$ In this study from category D drugs, doxycycline was the most frequently prescribed drug followed by tetracycline eye ointment, diazepam, gentamycin, and phenytoin. These drugs are considered to be risky in pregnancy.

The use of tetracycline and doxycycline are inappropriate since both drugs can cross the placenta and their use in second and third trimester pregnancy causes permanent discoloration of teeth, enamel hyperplasia and impaired fetal skeletal growth. The other drug gentamycin is known to cause oto toxicity in first trimester. ${ }^{23}$

Diazepam was used for the treatment of mild to severe preeclampsia. However, if diazepam is used for long period during pregnancy or at high doses which exceed $30 \mathrm{mg}$, it may be associated with a high incidence of physiological depression, the babies being likely to have a tendency to apnea, reluctance to feed and impaired hermogenesis. ${ }^{24}$ Moreover, the use of phenytoin in pregnancy has significant teratogenic effects on the fetus. It causes fetal hydantoin syndrome and multiple congenital anomalies in first-trimester and produces neurocognitive effects in second and third trimester gestations. ${ }^{23}$ The postpartum reports of the study patients were assessed but there was no such reports documented on patients' record cards. This could be the limitation of the study.

FDA category $\mathrm{X}$ drug was prescribed only in first trimester gestation. Misoprostol was the category X drug used by five women to terminate pregnancy. This is in line with Goldberg, Greenberg and Darney ${ }^{25}$ observation in which misoprostol was used most extensively for first-trimester medical abortions. But, in another study it was reported that misoprostol was used to induce labor in third trimester. ${ }^{19}$

Average numbers of drugs per prescription was within the range of WHO in first, second and third trimester with the average value of 1.41 . This value is not in line with the finding reported on pregnant women visiting antenatal clinic. ${ }^{21}$ Percentage of encounter with antibiotics prescribed was higher than WHO core drug prescribing indicators in first and third trimesters which show over use antibiotics.

The occurrence of injecttables was higher than the WHO standard in third trimester. The majority of these injecttables given to pregnant women were large volume parenteral. This might be due to an increased hyperemesis gravidum that need fluid maintenance. However, the use of injecttables may introduce a high concentration of drugs to the plasma, which could lead to toxicity in the pregnant women exposed. ${ }^{21}$ Percentage of drugs prescribed by generic name was almost the same across all trimesters, and the majority of them were prescribed by their generic name which is encouraging.

\section{CONCLUSION}

FDA category B drugs were the most frequently prescribed drugs. However, approximately half of the pregnant women encountered with drugs from category C, $\mathrm{D}$ and $\mathrm{X}$ which are thought to cause possible fetal harm. Hence, such inappropriate prescription of drugs should not be underestimated since it affects the life of both the mother and the fetus. Therefore, intensive assessment of pharmacotherapy given to pregnant women should be done with respect to the FDA risk category, the gestational period, and the risk-benefit balance of a drug before its prescription.

The prescribing trend among prescribers for pregnancy is more or less rational, but there is a lot to be improved. Antibiotics use was not within the range of WHO standard which indicates overuse of antibiotics. Moreover, percentage encounter with injection was higher in third trimester. Therefore, lack of awareness in respect to drug prescription and use should be improved with the proper implementation of information, education and Communication. 


\section{CONFLICT OF INTEREST}

The authors declare that there was no any financial or personal conflict of interest.

\section{ACKNOWLEDGEMENT}

The authors would like to thank Jimma University for sponsoring this study.

\section{Highlights of Paper}

- A total of 323 women received 456 medications during the specified study period.

- Among the pregnant women who got at least one medication during their ANC visit $43.96 \%$ were in their first trimester; $32.84 \%$ in their second trimester and $23.20 \%$ in their third trimester.

- FDA category B drugs (26.75\%) were the most commonly prescribed drugs.

- Cataegory D drugs, which are considered to be risky in pregnancy, including doxycycline, gentamicin, chlorpromazine, diazepam and phenytoin were prescribed.

\section{Author Profile}

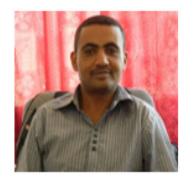

- Fanta Gashe, Presently he is working as lecturer, in Pharmacy Department, Jimma University, Ethiopia. Continuing and distance education coordinator of the department, conducting a research project on medicinal activities of medicinal plants, he has 5 nos. of journal paper currently and two more under publication; 4 nos. of abstract.

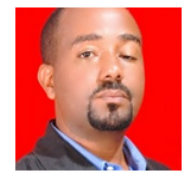

- Dereje Kebebe, Currently, he is working as lecturer in Jimma University, Ethiopia. He is just to start PHD in VLIR-UOS Institutional University which is a Cooperation programme with Jimma University. He has three journal publications.

\section{REFERENCES}

1. Wacha J, Szijarto A. Probiotics and pregnancy. Orvosi Hetilap. 2011; 152(11): 420-6.

2. European Medicines Agency: Committee for medicinal products for human use(2005), Guideline on the exposure to medicinal products during pregnancy, Westferry Circus, Canary Wharf, London, E14 4HB, UK, November 2004. Available from www.ema.europa.eu/docs/en_GB/guideline//WC500003329.pdf.

3. Yankowitz J. Use of medications in pregnancy: general principles, teratology, and current developments, In: J Yankowitz Niebyl JR. Drug therapy in pregnancy, Lippincott: Williams \& Wilkins; 2001. 129-32.

4. Lee E, Maneno M, Smith L, Weiss S, Zuckerman I, Wutoh A, et al. National Patterns of Medication use during Pregnancy. Pharmaco epidemiol Drug Saf. 2006; 15(1): 537-45

5. Lagoy CT, Joshi N, Cragan JD, Rasmussen SA. Medication use during pregnancy and lactation: an urgent call for public health action. J Women's Health 2005; 14(2): 104-9.

6. Sachdeva P, Patel BG, Patel BK. Drug use in pregnancy; a point to ponder. Indian J. Pharm. Sci. 2009; 71(1): 1-7.

7. Hansen WF, Yankowitz J. Pharmacologic therapy for medical disorders during pregnancy. Clin Obstet Gynecol. 2002; 45(1): 136-52.

8. Yankowitz J, Peacock AE, Hansen WF. Safe prescribing practices in pregnancy and lactation. J Midwifery Womens Health. 2002; 47(6): 409-421.

9. Gagne JJ, Maio V, Berghella V, Louis DZ, Gonnella JS. Prescription drug use in pregnancy: a population-based study in Regione Emilia-Romagna, Italy. Eur J Clin Pharmacol. 2008; 64(11): 1125-32.

10. Cooper WO, Hernandez-Diaz S, Arbogast PG, Dudley JA, Dyer S, Gideon PS et al. Major congenital malformations after first-trimester exposure to ACE inhibitors. N Engl J Med. 2006; 354(23): 2443-51.

11. Diaz H. Prescription of Medications during Pregnancy:Accidents, Compromises, and Uncertainties. Pharmaco epidemiol Drug Saf. 2006; 15(9): 613-7.

12. FDA Center for Drug Evaluation and Research (CDER), Center for Biologics Evaluation and Research (CBER). Guidance Evaluating the Risks of Drug Exposure in Human Pregnancies, US Department of Health and Human Services; 2005. pp 455-6. Available from www.fda.gov/downloads/ scienceresearch/specialtopics/womenshealthresearchucm 133359. pdf.
13. FDA. Pregnancy categories for prescription drugs. FDA Drug Bull. 1982; 12(1): 24-5.

14. Andrade SE, Davis RL, Cheetham TC, Cooper WO, Li DK, Amini T, et al. Medication Exposure in Pregnancy Risk Evaluation Program. Matern Child Health J. 2012; 16(7): 1349-54

15. Sharma R, Kapoor B, Verma U. Drug utilization pattern during pregnancy in North India. Indian J. Med. Sci. 2006; 66(7): 277-87.

16. Andrade SE, Gurwitz JH, Davis RL, Chan KA, Finkelstein JA, Fortman K, et al. Prescription drug use in pregnancy. Am J Obstet Gynecol. 2004; 191(2): 398-407.

17. Joshi H, Patel S, Patel K, Patel V. Drug Use Pattern during Pregnancy: A Prospective Study at Tertiary Care Teaching Hospital. NHL Journal of Medical Science 2012; 1(1): 14-7.

18. Belay M, Kahaliw W, Ergetie Z. Assessment of drug utilization pattern during pregnancy in Adama Riferral Hospital, Oromia Region, Ethiopia. Int J Pharm Sci Res. 2013; 4(5): 1905-11.

19. Lukas T, Fikadu D, Belachew G, Nigatu B. Drug utilization pattern and potential teratogenicity risk among pregnant women. The case of Hayder Referral Hospital, Ethiopia. Int J Pharm Sci Res. 2012; 3(1): 1371-8.

20. Oshikoya KA. Medication use assessment among pregnant women. Sri Lanka. J Obstet Gynaecol. 2012; 34(6): 84-98

21. Eze UI, Eferakeya AE, Oparah AC, Enato EF. Assessment of prescription profile of pregnant women visiting antenatal clinic. J. Pharm Pract. 2007; 5(3): $135-9$

22. Hussein JM, Workicho $A B$, Hisham SA. Medications use among pregnant women in Ethiopia: A cross sectional Study. J App Pharm Sci. 2013; 3(04): 116-23.

23. Manisha B, Dhasmana DC. Teratagenecity and Maternogenicity - Myths and Facts. Res. J. Pharm Biol Chem. 2014; 5(1): 452-69.

24. Leppée M, Culig J, Eric M, Sijanovic S. The effects of benzodiazepines in pregnancy. Acta Neurol Belg. 2010; 110(2): 163-7.

25. Goldberg AB, Greenberg MB, Darney PD. Misoprostol and Pregnancy. N Engl J Med. 2001; 344(1): 38-47. 